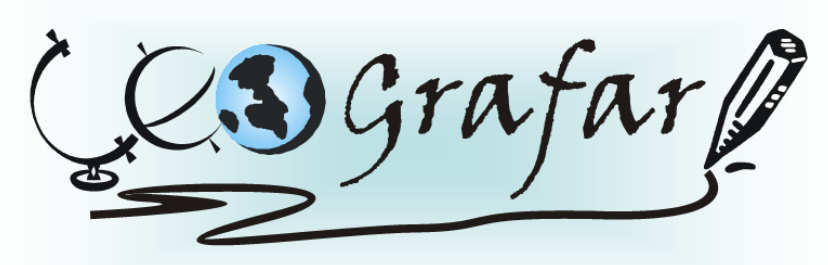

Revista Eletrônica do Programa de Pós-Graduação em Geografia - UFPR

\title{
VARIAÇÃO DOS ATRIBUTOS FÍSICOS DO SOLO DEVIDO AO TRÂNSITO DE PESSOAS EM TRILHA LOCALIZADA NA REGIÃO DE PARANAGUÁ - PR.
}

\author{
RONALDO FERREIRA MAGANHOTTO ${ }^{1}$ \\ LEONARDO JOSÉ CORDEIRO SANTOS ${ }^{2}$ \\ LUIZ CLAUDIO DE PAULA SOUZA ${ }^{3}$ \\ MARCO ANTONIO MIARA ${ }^{4}$
}

Resumo: A crescente demanda turística por áreas naturais motiva a implantação de trilhas, as quais devem estar ligadas a estudos prévios minimizando, assim, os impactos recorrentes a mesma. Esta pesquisa teve como objetivo avaliar as alterações nas propriedades físicas do solo diante do deslocamento de pessoas nas trilhas. Para isso, uma trilha foi utilizada como base para o estudo, sendo comparadas as condições de seu traçado e de sua faixa lateral. Conforme o método sugerido pela EMBRAPA, as variáveis verificadas reportaram-se à granulometria, quantidade de matéria orgânica, porosidade e densidade do solo. De posse destas informações constatou-se que a utilização da trilha além de influenciar no aumento da densidade, da microporosidade, na porcentagem de areia e argila agiu de forma contrária para a matéria orgânica macroporosidade, freqüência de raízes e porcentagem de silte. Desta forma, a correlação e a variação desses elementos facilitaram o entendimento da dinâmica pedológica perante a pressão exercida sobre o solo durante o deslocamento (pisoteio) de pessoas.

Palavras-Chave: Trilhas; Solos; Compactação.

\section{SOIL'S PHYSICAL CHARACTERISTICS VARIATIONS DUE TO THE FLOW OF PEOPLE TROUGH A TRACK LOCATED IN THE CITY OF PARANAGUA - PR}

\begin{abstract}
The increasing tourist demand looking for natural areas require the implementation of tracks, wich must be made after previous studies, minimizing the environmental impacts. The aim of this search is to study the changes at the soil's physical properties due to the flow of people on the tracks. A track was used as the research project, comparing trajectory and its width. According to Embrapa's method, the variations were based on the study of granulometry, the amount of organic material, porosity and density of the soil. These informations evidenced that the flow of people through the track contribuited to increase the level of density, microporosity, sand and clay percentage, acted against the organic material macroporosity, roots appearing and silte percentage. Therefore, analyzing the correlation and variations of these elements helped the understanding of the pedologic dynamic before putting pressure on the soil during the hiking.
\end{abstract}

Key-words: tracks; soil; compactaness.

\footnotetext{
${ }^{1}$ ronaldomaganhotto@yahoo.com.br

2 santos@ufpr.br

3 lcsouza@ufpr.br

${ }^{4}$ marmiara@yahoo.com.br
} 


\section{INTRODUÇÃO}

Atualmente, a degradação dos recursos naturais tem influenciado diretamente na qualidade de vida dos seres vivos, evidenciando-se assim a necessidade de certo equilíbrio entre a busca do desenvolvimento econômico e a conservação do meio.

A problemática evidenciada nos centros urbanos aliada aos diversos fatores como a valorização da natureza, tem contribuído para a demanda turística em áreas naturais. Entretanto, o uso abusivo destas áreas tem gerado inúmeros danos aos seus componentes ambientais.

Neste contexto, o desenvolvimento da atividade turística em áreas naturais necessita a inserção de uma série de elementos, como as trilhas, importantes pelo fato de proporcionarem um caminho para que as pessoas consigam desfrutar dos conjuntos paisagísticos de maneira organizada, segura e consciente.

Porém, um traçado quando mal planejado e ou implantado em locais inadequados pode resultar em problemas de maior amplitude como compactação e erosão dos solos, assoreamento dos rios dentre outros.

Estes impactos podem ser observados em vários locais, como na Serra do Mar, nas proximidades do Município de Curitiba, onde as condições sócioambientais favorecem essa realidade.

Contudo, para o planejamento dos traçados faz-se necessário o entendimento da dinâmica das propriedades físicas do solo, ou seja o conhecimento dos reflexos do deslocamento de pessoas sobre os traçados das trilhas é de fundamental importância para um manejo coerente com a preservação dos recursos naturais presentes no entorno da trilha.

Diante da importância de tal temática, o presente estudo foi realizado no Sítio Vovô Miguel, tendo como objetivo analisar o impacto do uso do solo como trilha sobre as propriedades físicas do solo.

A área de estudo encontra-se localizada no distrito de Alexandra, Município de Paranaguá, Figura 1. A propriedade situa-se nas encostas da Serra da Prata uma ramificação da Serra do Mar, a qual se identifica como um grande bioma terrestre com Floresta Ombrófila Densa e ecossistemas associados, apresentando 
peculiaridades históricas, climáticas, fisiográficas, culturais e ecológicas que a diferencia das demais regiões do Estado.

Tais características justificam também a realização desta pesquisa, uma vez que, pretende-se utilizar a propriedade para fins turísticos e científicos, orientando o manejo da propriedade neste diferentes fins.

Figura 1: Mapa de Localização do Sítio Vovô Miguel, município de Paranaguá, PR.

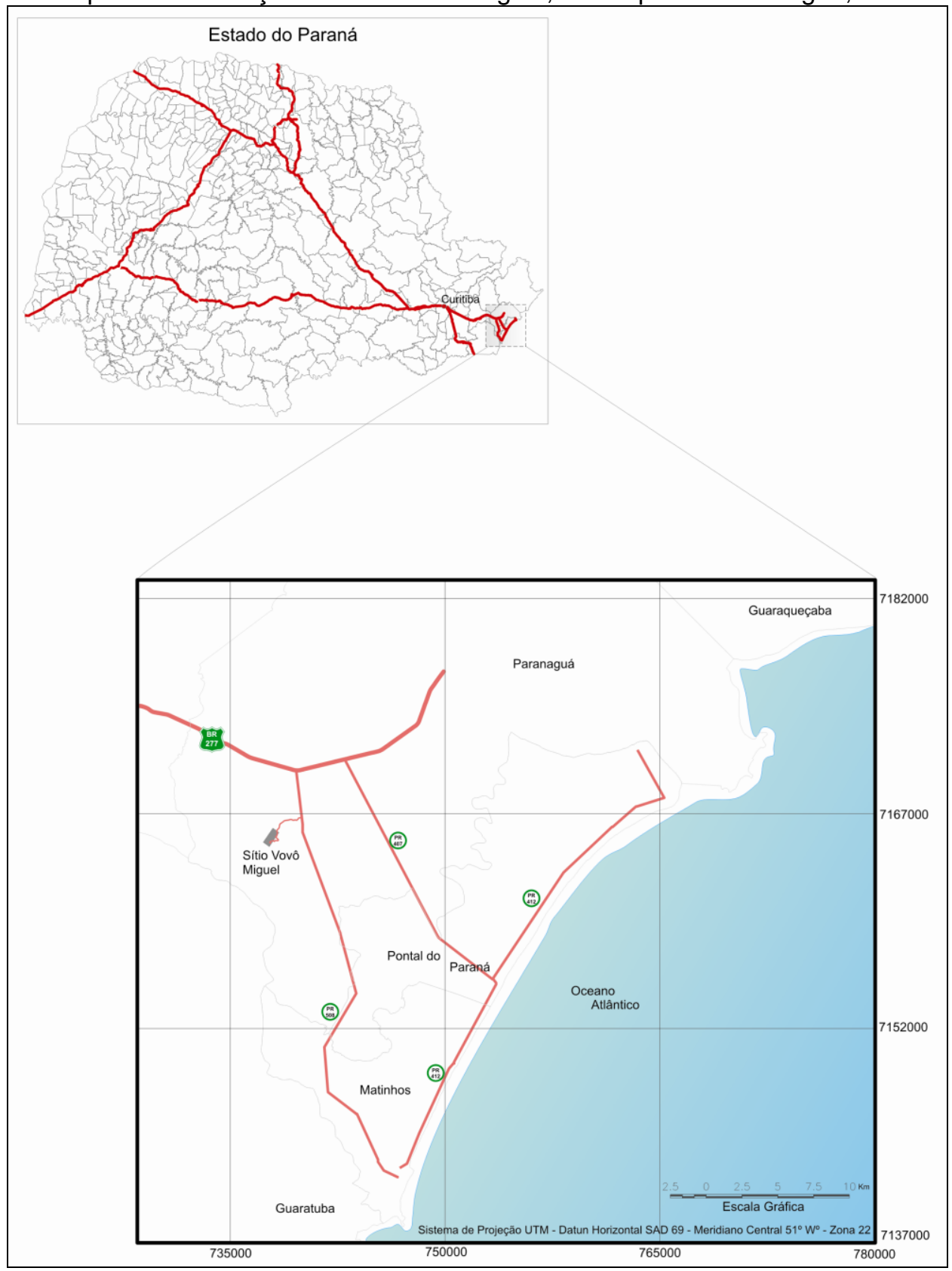

Organização: Maganhotto, R. e Miara, M. 


\section{O TURISMO E SUA RELAÇÃO COM AS TRILHAS}

Diante da complexidade da atividade turística e do elevado ritmo de crescimento do setor de serviços, os estudos na área de turismo mostram-se relevantes no sentido de estabelecer, ampliar e esclarecer as bases teóricas e práticas da atividade.

Vale destacar que o turismo, além dos benefícios econômicos, pode auxiliar na proteção dos recursos naturais. Além disso, pode facultar à manutenção da identidade das populações receptoras por meio de novas perspectivas sociais, como resultado do desenvolvimento econômico e cultural da região.

Em contrapartida, a falta de preocupação com o bem estar da população residente e com a preservação ambiental por parte dos administradores pode levar ao comprometimento das potencialidades naturais e culturais, dificultando 0 desenvolvimento coerente da atividade.

Conforme Oliveira e Serrano (1997), o ecoturismo é um segmento turístico que utiliza o patrimônio natural e cultural de forma sustentável, incentivando sua conservação por meio da conscientização ambiental e promoção do bem-estar das partes envolvidas.

Esse segmento, quando planejado, é visto como uma maneira de aliar a conservação e o desenvolvimento, pois configura-se como uma forma de utilização indireta dos recursos naturais.

Com o crescimento da atividade turística em áreas naturais, as trilhas, além de simples caminhos, passaram a ser instrumento de ligação entre o homem e a natureza. Ora utilizadas como atrativos principais, ora como secundário os traçados têm influenciado no aparecimento de novos praticantes.

A implantação de trilhas de forma desordenada e sem planejamento pode contribuir para o desencadeamento de impactos, potencializados pelo não entendimento da dinâmica física local. Além disso, a carência de monitoramento e manutenção são fatores determinantes à conservação destes ambientes. Desta forma evidencia-se uma série de problemas inerentes a abertura e utilização das trilhas. 
Segundo Pagani (1998), os impactos de maior expressão causados pela implantação de uma trilha são: compactação, que reduz a permeabilidade do solo favorecendo o processo erosivo; a degradação da vegetação através do choque mecânico direto e o comprometimento da fauna nos seus hábitos diários.

Ruschmann (1997) menciona a coleta e a destruição da vegetação, a erosão das encostas, devido ao mau traçado e à falta da drenagem, o alargamento e pisoteio nas trilhas, como sendo problemas relacionados ao mau uso do solo na implantação de trilhas em áreas naturais.

Conforme Kuss apud Takahashi (1998), o uso recreativo, ou seja, o caminhar de visitantes, pode influenciar na composição de espécies e na diversidade de vegetação, nas propriedades do solo e no comportamento de várias espécies da fauna silvestre.

Desta feita, evidencia-se uma série de publicações discutindo tal abordagem, Takahashi (1998) caracteriza os visitantes e avalia os impactos da visitação pública em duas unidades de conservação do Estado do Paraná; Boçon (2002) teve como base a caracterização de solos, vegetação e do público como indicadores no planejamento de trilhas interpretativas; Magro (1999) descreveu em sua tese os impactos do uso público na trilhas do Parque Nacional de Itatiaia; Pagani (1998) correlaciona as trilhas interpretativas da natureza e o ecoturismo;

Jorge (1985) ressalta que o uso desordenado dos solos, como a abertura de trilhas em locais impróprios, tem sido responsável pelo aparecimento de inúmeros problemas ambientais, como a compactação e a erosão dos solos.

Constata-se, portanto, que a implantação de trilhas pode provocar sérios impactos no solo, dentre os mais comuns está o processo de compactação do mesmo. Neste sentido, considerando a temática do presente trabalho, faz-se necessário uma abordagem sobre solos e suas propriedades físicas.

Lepsch (2002) definiu os solos como a massa natural resultante da ação do clima e da biosfera sobre a rocha. Afirma que os mesmos ocorrem em função de cinco fatores: clima, natureza dos organismos, material de origem, relevo e idade do lugar. Consequentemente, a variação destes elementos é responsável pelo 
surgimento de vários tipos de solos, os quais são compostos por partículas minerais (argila, areia e silte), materiais orgânicos, água e ar.

Logo a descrição dos solos tem como base a verificação de alguns elementos morfológicos referentes a cor, textura, estrutura, consistência e espessura dos horizontes.

Dentre estes, a cor é a mais facilmente percebida, o que resulta em muitos nomes populares como: terra roxa e terra preta. Sua determinação ocorre por meio de comparação com uma escala padrão.

A textura reportasse à proporção relativa das partículas primárias do solo (areia, silte e argila). As partículas de areia, argila e silte são aglomeradas em torrões, mas unidas com diferentes graus de adesão, tornando uns solos macios e outros mais duros.

A estrutura caracteriza-se pelo conjunto dos torrões (agregados) que aparecem naturalmente no solo, possuem tamanhos e formatos variados, podendo ser: prismáticas, colunar, em blocos, laminar e granular. Jorge (1985) cita que a estrutura do solo "regula a aeração, o suprimento de água, penetração das raízes, disponibilidade de nutrientes, atividade micro e macrobiológica e temperatura do solo".

Os poros no solo apresentam uma grande variação tanto no tamanho quanto na sua forma, desde alguns nanômetros de separação entre laminas de argila, ou alguns centímetros nas fissuras, até orifícios resultantes da atividade da mesofauna.

Quanto à porosidade do solo, Jorge (1985) conceitua-a como sendo a porção do solo não ocupada por partículas sólidas, e classifica-a em macroporosidade e microporosidade, onde a primeira é responsável pela circulação de ar e infiltração de água e a segunda é responsável pela retenção de água.

Tormena (1991), define macroporos como sendo poros com diâmetros suficientes para a ocorrência de fluxo canalizado em condições de não-equilíbrio. Os macroporos são funcionalmente classificados como poros de transmissão, importantes para o fluxo de água e ar no solo. A continuidade e ocorrência dos macroporos relacionam-se principalmente à presença de atividade biológica e de raízes. 
Para Gupta apud Tormena (1991), "os macroporos são sensíveis às cargas aplicadas no solo, sendo destruídos no primeiro estágio da compactação. Caracterizando, desta forma, os efeitos da compactação sobre a estrutura do solo".

Segundo Sanches (1981), a organização do solo em agregados estáveis, ou seja, a estrutura propriamente dita é um atributo de grande importância, pelo fato de a variação dos componentes estruturais influenciarem no processo de compactação.

Quando ocorre uma pressão sobre o solo, ou seja, quando um peso repousa acima dele, gera uma movimentação das partículas sólidas e da fase líquida, causando certas deformações e uma diminuição no seu volume, tornando-se uma massa de maior densidade (JORGE, 1985).

Desta forma, a compactação é entendida como uma reação e/ou uma resposta do solo à aplicação de cargas externas, modificando assim suas características. Ocorre primariamente devido à compressão e deformação das partículas do solo e compressão do ar e da água nos poros.

Outro elemento importante dentro deste processo é a textura, ou seja, a quantidade de argila, silte e areia num solo. No caso de um solo argiloso quando sofre certa pressão, suas partículas finas rolam para os espaços deixados pelas partículas grosseiras, como as areias, causando uma diminuição no seu volume, com conseqüente aumento na densidade. Este efeito nocivo é mais grave quando a pressão é exercida sobre solos úmidos.

Kertzman (1996),menciona alguns efeitos da compactação visíveis no campo, como: o empoçamento de água, erosão pluvial excessiva, o endurecimento do solo e a diminuição da ocorrência e do porte das raízes.

O mesmo autor afirma que "os efeitos da compactação são verificados pelo incremento na densidade do solo, que indica a diminuição da porosidade. Praticamente todos os trabalhos sobre o tema apresentam valores de densidade e porosidade do solo como indicadores de compactação".

\section{CARACTERIZAÇÃO DA ÁREA E OBJETO DE ESTUDO.}


A área de estudo está localizada no Município de Paranaguá, Colônia Santa Cruz, nas coordenadas UTM 737.100 m e $738.230 \mathrm{~m}$ S e $7.166 .000 \mathrm{~m}$ e 7.167 .000 m, próximo à estação de tratamento de água - Águas de Paranaguá - a 2,5km do asfalto, na rodovia de Alexandra - Matinhos em direção ao morro Inglês, em estrada macadamizada. Informações, estas, representadas espacialmente na Figura 1.

Por meio de uma entrevista não estruturada, realizada com o senhor Deodato Miguel de Paula Souza, professor aposentado, do Curso de Engenharia Agronômica, da UFPR e UEPG, e atual proprietário do sítio. A área pode ser descrita da seguinte forma: com aproximadamente 48 ha, cerca de $40 \%$ da área apresenta relevo ondulado à forte ondulado, tendo como base geológica granitos pórfiros, dos quais desenvolveram na região solos Argissolos Vermelho Amarelos associados a pequenas manchas de Latossolos Amarelo e Cambissolos Substrato Granito. A cobertura vegetal presente nesta porção dividem-se em florestas primárias e secundárias. Com mesma origem geológica e de pedogênese basicamente composta de solos Argissolos Vermelho Amarelos, outros $40 \%$ da área estão situados em relevo ondulado sob uma vegetação composta de culturas e capoeira. Entremeando as posições mais movimentadas, cerca de $20 \%$ da área apresenta relevo praticamente plano 0 e 3\%, geologicamente resultante de deposições holocênicas, originando, assim, solos Gley Pouco Húmico e Aluviões, compondo a área de várzea drenada, esta classificação dos solos segue o Sistema Brasileiro de Classificação de Solos (EMBRAPA, 2006). A cultura de Palmito Pupunha, tanques e represas são os usos destinados a esta faixa.

\section{TRILHA DE ESTUDO}

A trilha escolhida para o estudo, Figura 2, encontra-se na parte de relevo ondulado da propriedade, sob uma faixa de solo Argissolos Vermelho-Amarelo, utilizado para o plantio de palmáceas. Seu traçado possui aproximadamente $60 \mathrm{~m}$ de comprimento e $1 \mathrm{~m}$ de largura com declividade variando de 10 a $15 \%$. A trilha atualmente é usada pelos funcionários do sítio, já que esta liga o depósito de adubos às demais áreas cultivadas. Assim, o processo de compactação neste traçado se deu pela pressão exercida durante o caminhamento dos funcionários já que a passagem de maquinas pela mesma não é permitido. Com a implantação da 
atividade turística, a trilha além de servir como atrativo turístico auxiliará o deslocamento dos visitantes na propriedade.

Figura 2 - Trilha de Estudo

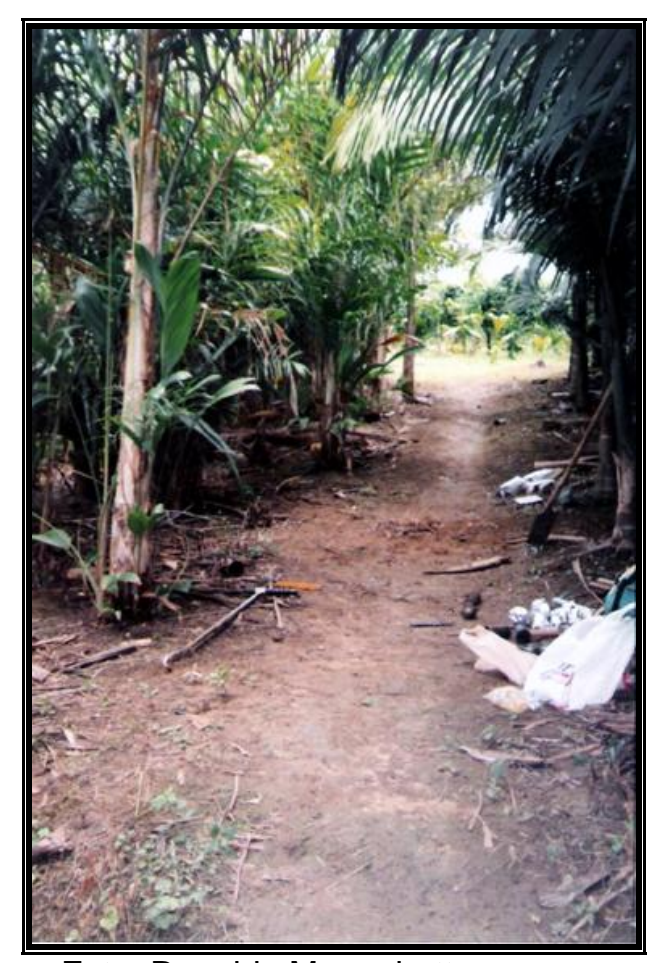

Foto: Ronaldo Maganhotto

\section{PROCEDIMENTOS METODOLÓGICOS}

Para a concretização dos objetivos pré-determinados foi necessário identificar elementos que demonstrassem a alteração das propriedades do solo devido à pressão exercido sobre o mesmo. Neste contexto, utilizaram-se a análises descrita pela Empresa Brasileira de Pesquisa Agropecuária EMBRAPA (1984), e seguida por Takahashi (1998), em que os índices de granulometria, matéria orgânica, densidade do solo e porosidade foram os indicadores avaliados.

\section{ATIVIDADES REALIZADAS EM CAMPO}

O reconhecimento visual da área, efetuado inicialmente, almejou a identificação de um traçado pisoteado com um entorno próximo do natural, possibilitando, assim, amostras de solos de situações diferentes passíveis de comparação. 
A trilha de estudo corta a cultura de palmito e apresenta as condições almejadas para realização da pesquisa. O traçado, alterado devido à pressão exercida sobre o mesmo e a área testemunho, faixa lateral a trilha utilizada atualmente como área de cultivo de palmito e com condições pedológicas próxima do natural, essas informações encontram retratadas na Figura 3.

Figura 3 -Traçado da Trilha e Área Testemunho

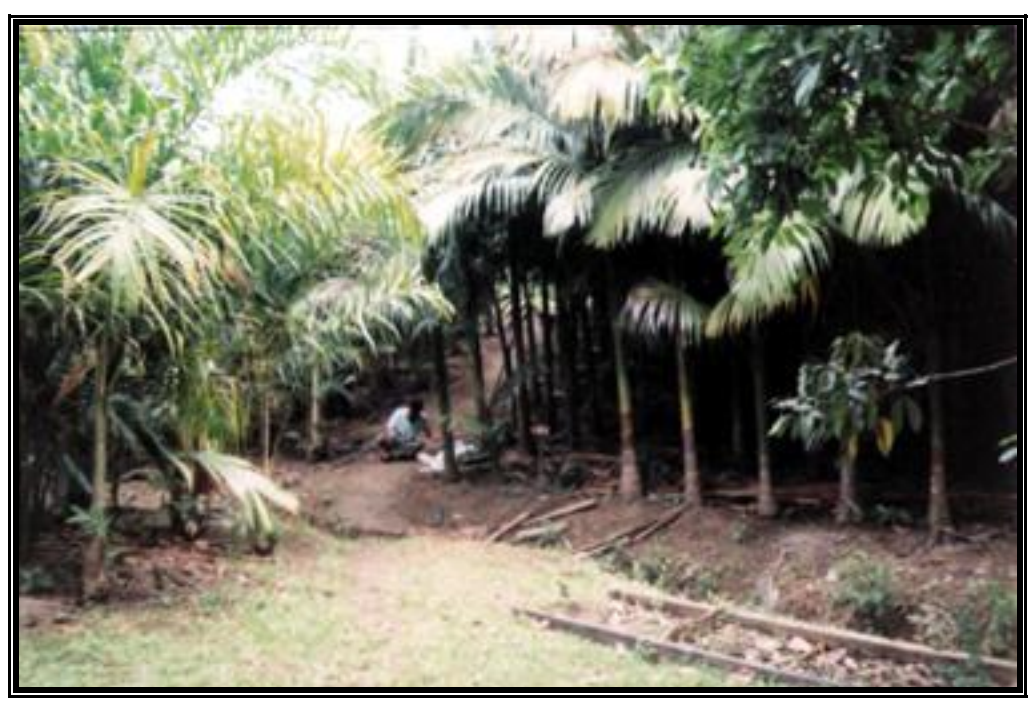

Foto: Ronaldo Maganhotto

Para a determinação dos pontos de coleta foi realizada uma sondagem com trado holandês para identificar os locais e as profundidades de melhor aptidão para coleta, como demonstrado na Figura 4. 


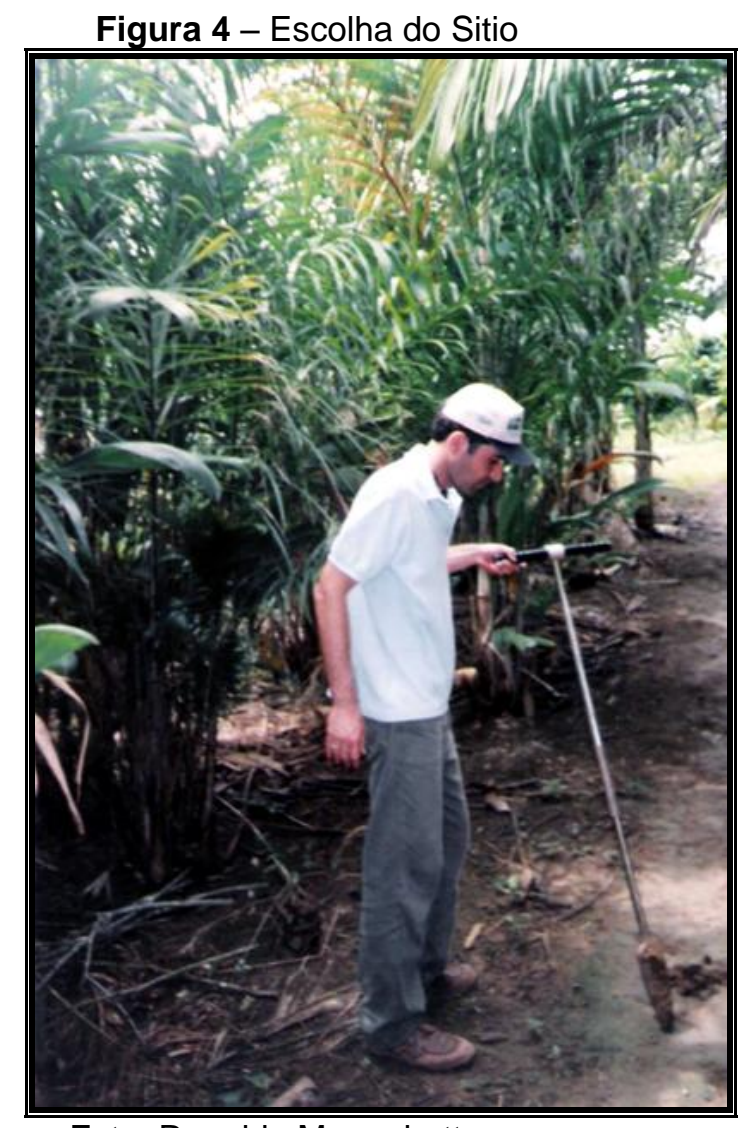

Foto: Ronaldo Maganhotto

Foram definidos quatro pontos de coleta sendo dois no traçado e dois na faixa lateral. As amostras foram retiradas de três níveis de profundidade (0-5, 5-10, 10-15 cm) de ambas as situações, com três repetições, podendo assim tirar uma média do resultado e/ou eliminar um dado não compatível. Esses procedimentos encontram-se representados nas Figuras 5 e 6.

Figura 5 - Trincheira Traçado da Trilha

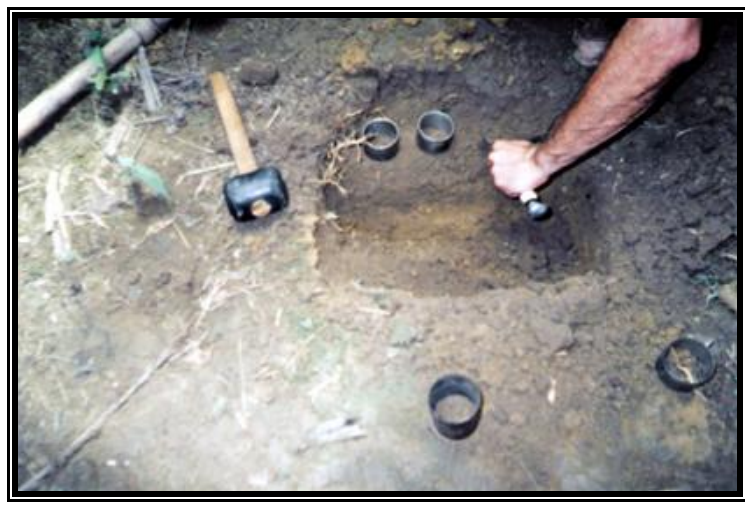

Foto: Ronaldo Maganhotto
Figura6 - Trincheira Área Testemunho

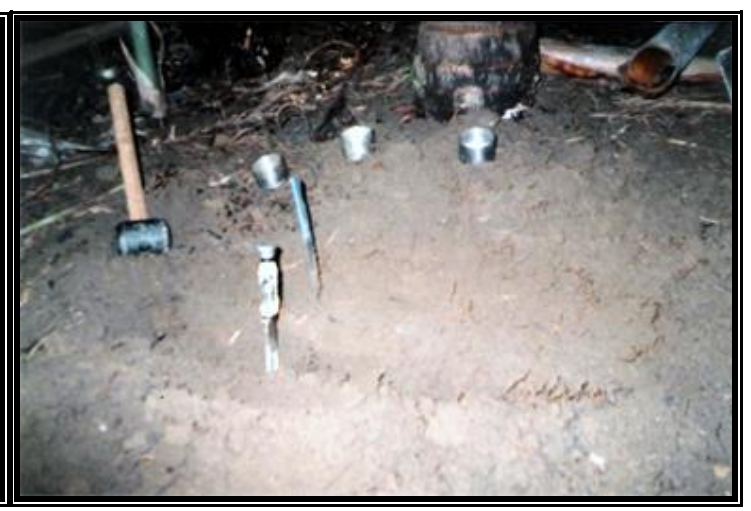

Foto: Ronaldo Maganhotto 
Equipamentos de auxílio em campo como clinômetro, para identificar o grau de declividade do terreno; trado holandês, para sondagem e anéis volumétricos, para coletar amostras indeformadas de solo, foram utilizados nessa fase da pesquisa.

\section{ATIVIDADES REALIZADAS EM LABORATÓRIO}

Após a coleta das amostras de solo em campo, foram realizadas análises para verificar os seguintes indicadores: textura, porosidade, densidade do solo e quantidade de matéria orgânica. Estes procedimentos foram realizado nos Laboratório de Física do Solo e de Fertilidade do Solo, do Curso de Engenharia Agronômica da UFPR.

Os procedimentos utilizados para a realização das análises estão de acordo com a metodologia seguida pela EMBRAPA descrita no Manual de Métodos de Análise do Solo (1997).

\section{RESULTADOS E DISCUSSÕES}

Os dados obtidos durante a pesquisa foram descritos nos quadros que se seguem, com o intuito de facilitar a leitura e a compreensão.

\section{Análise Morfológica}

Durante a coleta e a descrição do material em campo foi possível verificar algumas diferenças entre as duas faixas territoriais, ocasionadas pela diferente forma de uso.

Durante as sondagem em ambas as situações (traçado e área testemunho) verificou-se que as características morfológicas referentes a estrutura, cor e presença de raízes diferenciavam-se apenas nas primeiras profundidades, precisamente até os $15 \mathrm{~cm}$. Confirmando as informações encontradas na literatura que afirmam esta profundidade como sendo sensível a atividade humana. 
A descrição morfológica da área testemunho e do traçado da trilha apresenta diferentes resultados quanto à cor, à estrutura e à presença de raízes, dados constatados a partir das informações contidas nos quadros 1 e 2.

QUADRO 1 - RESULTADOS DA ANÁLISE MORFOLÓGICA DA ÁREA TESTEMUNHO

\begin{tabular}{|c|c|c|c|}
\hline \multicolumn{4}{|c|}{ ÁREA TESTEMUNHO } \\
\hline PROFUNDIDADE & COR & PRESENÇA DE RAÍZES & ESTRUTURA \\
\hline $0-5 \mathrm{~cm}$ & $5 Y R 3 / 1$ & Altamente desenvolvida & Grumosa - blocos \\
\hline $5-10 \mathrm{~cm}$ & $5 Y R 4 / 2$ & Moderada & Grumosa \\
\hline $10-15 \mathrm{~cm}$ & $5 Y R 5 / 4$ & Pouco desenvolvida & Blocos subangualres $-3 \mathrm{~cm}$ \\
\hline
\end{tabular}

QUADRO 2 - RESULTADOS DA ANÁLISE MORFOLÓGICA DO TRAÇADO DA TRILHA

\begin{tabular}{|c|c|c|c|}
\hline \multicolumn{5}{|c|}{ TRAÇADO DA TRILHA } \\
\hline PROFUNDIDADE & COR & PRESENÇA DE RAIZES & ESTRUTURA \\
\hline $0-5 \mathrm{~cm}$ & $5 Y R 3 / 2$ & Pouco freqüente & $\begin{array}{c}\text { Blocos subangualres }-3 \\
\mathrm{~cm}\end{array}$ \\
\hline $5-10 \mathrm{~cm}$ & $5 Y R 4 / 4$ & Pouco freqüente & Maciça \\
\hline $10-15 \mathrm{~cm}$ & $7,5 Y R 5 / 6$ & Ausente & $\begin{array}{c}\text { Blocos subangualres }-3 \\
\mathrm{~cm}\end{array}$ \\
\hline
\end{tabular}

Observa-se nos quadros 1 e 2 que a cor teve pouca variação, tendo como mudança relevante na profundidade de 10 a $15 \mathrm{~cm}$, onde a área testemunho tem a cor classificada como 5YR5/4 e o traçado da trilha como 7,5Y5/4.

Quanto à presença de raízes, evidencia-se menor ocorrência destas no traçado da trilha em relação à área testemunho. As alterações ocorrem nas três profundidades, passando de altamente desenvolvido para pouco freqüente na profundidade de 0 a $5 \mathrm{~cm}$; de moderada para pouco freqüente de 5 a $10 \mathrm{~cm} \mathrm{e}$ finalmente de pouco desenvolvida para ausente de 10 a $15 \mathrm{~cm}$.

A estrutura mostra resultados diferentes de uma situação para outra apenas na primeira e na segunda profundidade. Na primeira profundidade, de 0 a $5 \mathrm{~cm}$, a estrutura da área testemunho é identificada como sendo grumosa em blocos, e no traçado da trilha como blocos subangulares de $3 \mathrm{~cm}$. Na segunda profundidade, de 5 a $10 \mathrm{~cm}$, nota-se que a área testemunho é classificada como grumosa, enquanto que no traçado da trilha é maciça. 
Pode-se observar que os tráfegos dos funcionários do sítio ocasionaram algumas mudanças nas características morfológicas do solo situado nos primeiros $15 \mathrm{~cm}$ da camada superficial, realidade que confirma a sensibilidade do solo ao deslocamento de pessoas nesses primeiros centímetros.

\section{Análise Granulométrica}

Ao analisar o quadro 3 nota-se que a grande diferença dos valores

granulométricos entre as formas de uso está na porcentagem de argila e silte.

Quadro 3 - Resultados Granulométricos Referentes a Área Testemunho e ao Traçado

\begin{tabular}{|c|ccc|ccc|}
\hline \multicolumn{7}{|c|}{ GRANULOMETRIA } \\
\hline \multirow{2}{*}{ PROFUNDIDADE } & \multicolumn{3}{|c|}{ Área testemunho } & \multicolumn{3}{c|}{ Traçado da trilha } \\
\cline { 2 - 8 } & ARGILA & AREIA & SILTE & ARGILA & AREIA & SILTE \\
\hline $0-5 \mathrm{~cm}$ & $18 \%$ & $56,4 \%$ & $25,6 \%$ & $22 \%$ & $58,2 \%$ & $19,8 \%$ \\
\hline $5-10 \mathrm{~cm}$ & $20 \%$ & $49,4 \%$ & $30,6 \%$ & $28 \%$ & $51,2 \%$ & $20,8 \%$ \\
\hline $10-15 \mathrm{~cm}$ & $14 \%$ & $50,8 \%$ & $35,2 \%$ & $26 \%$ & $51,4 \%$ & $22,6 \%$ \\
\hline
\end{tabular}

Na profundidade de 0 a $5 \mathrm{~cm}$, na área testemunho, o valor da argila é de $18 \% \mathrm{e}$ no traçado é de $22 \%$. De 5 a $10 \mathrm{~cm}$ o valor na primeira situação é de $20 \%$, enquanto na segunda é $28 \%$. E finalmente de 10 a $15 \mathrm{~cm}$ a faixa lateral, ou seja, a área testemunho, apresenta $14 \%$ de argila e o traçado, $26 \%$. Os valores de silte, como já foram citados, também variaram da área testemunho para o traçado da trilha nas três profundidades. Foram obtidos os seguintes valores: na primeira profundidade $25,6 \%$ e $19,8 \%$; na segunda 30,6 e $20,8 \%$ e finalmente na terceira profundidade 35,2 e $22,6 \%$.

Diante desses dados percebe-se que a pressão exercida através do deslocamento das pessoas tem contribuído significativamente no aumento da porcentagem de argila e no decréscimo da porcentagem de silte. Esta alteração afeta diretamente na permeabilidade do solo condicionando o processo de compactação. 


\section{Matéria Orgânica}

A matéria orgânica do solo concentra-se principalmente em sua superfície, fruto da decomposição de galhos, folhas etc. Desta forma, a análise da quantidade desse elemento é de extrema importância para verificação da alteração do solo. 0 quadro 4 registra a quantidade de matéria orgânica encontrada tanto na área testemunho quanto no traçado da trilha.

Quadro 4-Quantidade de Matéria Orgânica Encontrada na Área Testemunho e no Traçado

\begin{tabular}{|c|c|c|}
\hline \multicolumn{3}{|c|}{ MATÉRIA ORGÂNICA } \\
\hline PROFUNDIDADE & ÁREA TESTEMUNHO & TRAÇDO DA TRILHA \\
\hline $0-5 \mathrm{~cm}$ & $28,1 \mathrm{~g} / \mathrm{dm}^{3}$ & $24,5 \mathrm{~g} / \mathrm{dm}^{3}$ \\
\hline $5-10 \mathrm{~cm}$ & $20,8 \mathrm{~g} / \mathrm{dm}^{3}$ & $20,8 \mathrm{~g} / \mathrm{dm}^{3}$ \\
\hline $10-15 \mathrm{~cm}$ & $20,2 \mathrm{~g} / \mathrm{dm}^{3}$ & $8,1 \mathrm{~g} / \mathrm{dm}^{3}$ \\
\hline
\end{tabular}

Ao avaliar as duas formas de uso estudadas, evidencia-se que quantidade de matéria orgânica apresenta uma leve variação de seus valores nas duas profundidades extremas, a de 0 a $5 \mathrm{~cm}$ e a de 10 a $15 \mathrm{~cm}$. Na primeira profundidade o valor referente à matéria orgânica da área testemunho é de $28,1 \mathrm{~g} / \mathrm{dm}^{3}$ e $24 \mathrm{~g} / \mathrm{dm}^{3}$ para o traçado da trilha. Logo, na profundidade de 10 a $15 \mathrm{~cm}$ os valores são de 20,2 e de 8,1 .

\section{Densidade do Solo}

A densidade é outro elemento importante para verificação do comportamento do solo. Como já foi comentado, existem duas formas de quantificar a densidade: a densidade real, que se obtém através de amostras deformadas (partículas do solo) e a densidade aparente, que se dá através de amostras indeformada coletadas em anéis volumétricos.

Ao analisar os dados mostrados nos quadros 5 e 6 verifica-se que a faixa de solo utilizada como trilha teve valores maiores que a área testemunho.

Comparando a densidade real, nota-se que a área testemunho apresentou índices menores que o traçado da trilha, confirmando que a pressão exercida sobre o solo durante o deslocamento das pessoas tem uma interferência direta neste 
elemento. Enquanto a área testemunho demonstrou 2,35 g/ $\mathrm{cm}^{3}$ para as profundidades de 0 a $5 \mathrm{~cm}$ e 10 a $15 \mathrm{~cm}$, verificou-se para o traçado da trilha 2,5 $\mathrm{g} / \mathrm{cm}^{3}$ e 2,59 g/ $/ \mathrm{cm}^{3}$. Logo a variação na profundidade de 5 a $10 \mathrm{~cm}$ apresentou um intervalo maior sendo registrado, $2,17 \mathrm{~g} / \mathrm{cm}^{3}$ para a área testemunho e $2,5 \mathrm{~g} / \mathrm{cm}^{3}$ para o traçado da trilha.

Quadro 5 - Resultados Referentes à Densidade real da Área Testemunho e do Traçado

\begin{tabular}{|c|c|c|}
\hline \multicolumn{3}{|c|}{ DENSIDADE REAL } \\
\hline PROFUNDIDADE & ÁREA TESTEMUNHO & TRAÇADO DA TRILHA \\
\hline $0-5 \mathrm{~cm}$ & $2,35 \mathrm{~g} / \mathrm{cm}^{3}$ & $2,5 \mathrm{~g} / \mathrm{cm}^{3}$ \\
\hline $5-10 \mathrm{~cm}$ & $2,17 \mathrm{~g} / \mathrm{cm}^{3}$ & $2,5 \mathrm{~g} / \mathrm{cm}^{3}$ \\
\hline $10-15 \mathrm{~cm}$ & $2,35 \mathrm{~g} / \mathrm{cm}^{3}$ & $2,59 \mathrm{~g} / \mathrm{cm}^{3}$ \\
\hline
\end{tabular}

Baseando-se nos resultados obtidos na análise da densidade aparente (quadro 6), nota-se que a área testemunho e o traçado da trilha mostram os seguintes resultados: na profundidade de 0 a $5 \mathrm{~cm}$ a área testemunho apresenta $1,16 \mathrm{~g} / \mathrm{cm}^{3}$ e 0 traçado $1,33 \mathrm{~g} / \mathrm{cm}^{3}$; de 5 a $10 \mathrm{~cm}$ apresentaram $1,21 \mathrm{~g} / \mathrm{cm}^{3}$ e $1,38 \mathrm{~g} / \mathrm{cm}^{3}$ e na terceira profundidade $1,26 \mathrm{~g} / \mathrm{cm}^{3}$ e $1,49 \mathrm{~g} / \mathrm{cm}^{3}$.

Quadro 6 - Resultados referentes a Densidade Aparente

\begin{tabular}{|c|c|c|}
\hline \multicolumn{3}{|c|}{ DENSIDADE APARENTE } \\
\hline PROFUNDIDADE & ÁREA TESTEMUNHO & TRAÇADO DA TRILHA \\
\hline 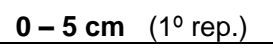 & $1,18 \mathrm{~g} / \mathrm{cm}^{3}$ & $1,34 \mathrm{~g} / \mathrm{cm}^{3}$ \\
\hline $0-5 \mathrm{~cm} \quad$ (2o rep.) & $1,11 \mathrm{~g} / \mathrm{cm}^{3}$ & $1,29 \mathrm{~g} / \mathrm{cm}^{3}$ \\
\hline $0-5 \mathrm{~cm} \quad$ (3을. & $1,20 \mathrm{~g} / \mathrm{cm}^{3}$ & $1,36 \mathrm{~g} / \mathrm{cm}^{3}$ \\
\hline Média & $1,16 \mathrm{~g} / \mathrm{cm}^{3}$ & $1,33 \mathrm{~g} / \mathrm{cm}^{3}$ \\
\hline $5-10 \mathrm{~cm}$ (1ㅇep.) & $1,18 \mathrm{~g} / \mathrm{cm}^{3}$ & $1,41 \mathrm{~g} / \mathrm{cm}^{3}$ \\
\hline $5-10 \mathrm{~cm}$ (2o rep.) & $1,18 \mathrm{~g} / \mathrm{cm}^{3}$ & $1,34 \mathrm{~g} / \mathrm{cm}^{3}$ \\
\hline $5-10 \mathrm{~cm}$ (3으 rep.) & $1,29 \mathrm{~g} / \mathrm{cm}^{3}$ & $1,40 \mathrm{~g} / \mathrm{cm}^{3}$ \\
\hline Média & $1,21 \mathrm{~g} / \mathrm{cm}^{3}$ & $1,38 \mathrm{~g} / \mathrm{cm}^{3}$ \\
\hline $10-15 \mathrm{~cm}$ (1으. rep.) & $1,32 \mathrm{~g} / \mathrm{cm}^{3}$ & $1,47 \mathrm{~g} / \mathrm{cm}^{3}$ \\
\hline $10-15 \mathrm{~cm}$ (2o rep.) & $1,25 \mathrm{~g} / \mathrm{cm}^{3}$ & $1,52 \mathrm{~g} / \mathrm{cm}^{3}$ \\
\hline $10-15 \mathrm{~cm}$ (3o rep.) & $1,23 \mathrm{~g} / \mathrm{cm}^{3}$ & $1,49 \mathrm{~g} / \mathrm{cm}^{3}$ \\
\hline Média & $1,26 \mathrm{~g} / \mathrm{cm}^{3}$ & $1,49 \mathrm{~g} / \mathrm{cm}$ \\
\hline
\end{tabular}




\section{Porosidade}

A porosidade é outra característica tida como indicadora de danos e impactos no solo, pois a sua alteração é imediata e de fácil verificação. O quadro abaixo comprova demostrando sua variação através dos resultados das análises. Ao verificarmos o quadro 7 percebe-se que a porosidade do solo de ambas as situações apresentam valores variados tanto para a microporosidade quanto para macroporosidade. Ao observar a macro percebe-se que o valor da área testemunho nos primeiros $5 \mathrm{~cm}$ é maior que a do traçado da trilha. Situação inversa ocorre com a microporosidade, que é maior nos primeiros $5 \mathrm{~cm}$. Assim, os valores médios são os seguintes: de 0 a $5 \mathrm{~cm}$ de profundidade a macroporosidade na área testemunho é de 21,2 , enquanto na outra forma de uso é de 5,1 . De 5 a $10 \mathrm{~cm}$ a macro difere de 7,4 para 12,5 e na profundidade seguinte os resultados obtidos foram 6,4 e 3,7. Quanto a microporosidade assume os seguintes valores, na primeira profundidade é de 36,8 para a faixa lateral e de 39,9 para o traçado. Na segunda os valores respectivos são 38,1 e 39 e na terceira profundidade os valores obtidos são os seguintes 30,7 e 39,8 .

Quadro 7 - Resultados da Porosidade da Área Testemunho e do Traçado

\begin{tabular}{|c|c|c|c|c|c|c|}
\hline \multicolumn{7}{|c|}{ POROSIDADE } \\
\hline \multirow{2}{*}{ PROFUNDIDADE } & \multicolumn{3}{|c|}{ ÁREA TESTEMUNHO } & \multicolumn{3}{|c|}{ TRAÇADO DA TRILHA } \\
\hline & Macro & Micro & Total & Macro & Micro & Total \\
\hline $0-\mathbf{5} \mathbf{~ c m} \quad\left(1^{\circ}\right.$ rep. $)$ & 23,4 & 37,7 & 61,1 & 6,3 & 40 & 46,3 \\
\hline $0-5 \mathrm{~cm} \quad$ (2 rep.) & 22,2 & 35,2 & 57,4 & 6,4 & 39 & 45,4 \\
\hline $0-5 \mathrm{~cm} \quad$ (3 rep.) & 18,1 & 37,6 & 55,7 & 2,8 & 40,9 & 43,7 \\
\hline Média & 21,2 & 36,8 & 58 & 5,1 & 39,9 & 45,1 \\
\hline $\mathbf{5 - 1 0} \mathbf{~ c m} \quad$ (1으. rep.) & 7,7 & 37,6 & 45,3 & 11,3 & 38,5 & 49,8 \\
\hline $5-10 \mathrm{~cm} \quad$ (2 rep.) & 8,6 & 37,5 & 46,1 & 14 & 38,4 & 52,4 \\
\hline $5-10 \mathrm{~cm} \quad$ (3 rep.) & 5,9 & 39,3 & 45,2 & 12,3 & 39,7 & 52 \\
\hline Média & 7,4 & 38,1 & 44,5 & 12,5 & 39,9 & 51,5 \\
\hline $10-15 \mathrm{~cm}$ (1 rep.) & 4,3 & 33,3 & 37,6 & 4,6 & 35,9 & 40,5 \\
\hline $10-15 \mathrm{~cm}$ (2 rep.) & 6,3 & 29,8 & 36,1 & 3,2 & 37,7 & 40,9 \\
\hline $10-15 \mathrm{~cm}$ (3 rep.) & 8,8 & 29,2 & 38 & 3,4 & 34,6 & 38 \\
\hline Média & 6,4 & 30,7 & 37,2 & 3,7 & 36 & 39,8 \\
\hline
\end{tabular}

Logo a porosidade total da área testemunho apresenta maior valor que a do traçado apenas na primeira profundidade, onde os resultados respectivos foram 58 e 45,1. Já na segunda profundidade os valores alteraram para 44,5 na área 
testemunho e 51,5 no traçado da trilha. E finalmente na terceira profundidade os dados obtidos foram 37,2 e 39,8 .

\section{SÍNTESE DOS RESULTADOS E CONSIDERAÇÕES FINAIS}

As análises permitiram verificar que mesmo a trilha não tendo um uso abusivo quanto ao tráfego de pessoas, há alterações nos indicadores selecionados. Esta condição demonstra a susceptibilidade do solo a impactos perante um fluxo constante de pessoas.

Descrevem-se a seguir algumas correlações existentes entre os resultados morfológicos (cor, estrutura e presença de raízes), granulométricos, quantidade de matéria orgânica, densidade e porosidade.

Com base na análise do quadro e da descrição referente aos elementos morfológicos verificam-se algumas alterações geradas pela pressão exercida durante o tráfego de pessoas. A alteração ocorrida na terceira profundidade, onde esta passou de 5YR 5/4 na área testemunho para 7,5YR 5/6 no traçado, pode estar relacionada com a permeabilidade reduzida nas primeiras profundidades $(0$ a $10 \mathrm{~cm})$ do traçado da trilha.

Evidencia-se a partir dos resultados que as raízes encontram-se em maior número na área testemunho, ao contrário do traçado, que apresenta uma concentração reduzida. Pelo fato de o sistema radicular estar exposto superficialmente, tornando-se sensível ao pisoteio gerado durante o deslocamento das pessoas, o que reduziu desta forma sua freqüência. Além desta influência direta, a alteração pode também estar ligada ao aumento da densidade do solo e a outros fatores como alteração na porosidade, que podem tornar o solo resistente à penetração.

A pressão ocasionada pelo peso das pessoas durante seu deslocamento fez com que houvesse uma reorganização das partículas do solo, modificando desta forma sua estrutura nas duas primeiras profundidades analisadas. Esta alteração é confirmada a partir dos dados visualizados no Quadro 1 que descreve os resultados morfológicos. 
Os resultados das análises realizadas demonstraram, também, alterações na granulometria, ou seja, na porcentagem de argila, areia e silte. Estes elementos são os que compõem a fase sólida do solo. Constatou-se por meio das análises o aumento na porcentagem de argila no traçado da trilha e o decréscimo proporcional na porcentagem de silte, situação que nos permite concluir que quanto maior a porcentagem de argila, maior é sua susceptibilidade à compactação.

O deslocamento e a movimentação de pessoas impedem o acúmulo de resíduos vegetais no traçado da trilha, ao contrário da faixa lateral (área testemunho), onde estes permanecem em repouso, decompondo e incorporando ao solo como matéria orgânica (carbono). A perda de carbono do solo influencia na sua recuperação, pelo fato da sua regeneração estar relacionada à baixa densidade do solo e à alta taxa de carbono disponível. Desta forma, nota-se um decréscimo no conteúdo de matéria orgânica no traçado da trilha, o que contribui negativamente na reestruturação do solo. Os dados descritos no Quadro 4 referente à quantidade de matéria orgânica certificam estas informações.

O solo tornou-se mais denso, ou seja, passou a acomodar uma maior quantidade de matéria num determinado espaço mediante a pressão ocasionada pelo deslocamento das pessoas. Assim, o traçado da trilha, que é a faixa que sofre pressão diretamente, é mais denso em relação à área testemunho nas três profundidades. Desta forma, quanto maior o valor da densidade do solo, maior a sua resistência à penetração e maior será a compactação.

Constata-se, diante dos resultados apresentados no capítulo anterior, que o peso das pessoas exercendo certa pressão tende a alterar algumas propriedades físicas do solo, inclusive a porosidade, que é um indicador de fácil percepção. A medida que o solo é pressionado ele tende a ficar mais denso, ou seja, a matéria sólida tende a ocupar os espaços vazios, e conseqüentemente os poros maiores são ocupados por partículas de solo.

Pode-se observar que no traçado da trilha a microporosidade é maior que a microporosidade da área testemunho, nas três profundidades. Já a macroporosidade teve um grande decréscimo na primeira profundidade $(0$ a $5 \mathrm{~cm})$, confirmando que a pressão exercida sobre o solo afeta primeiramente os macroporos, reduzindo-os a microporos, modificando desta forma a permeabilidade do solo e sua resistência à 
penetração das raízes. A permeabilidade é reduzida pelo fato da diminuição dos macroporos, que são responsáveis pela circulação de água e ar, e pelo aumento dos microporos, que são responsáveis pela retenção de água. Nestas condições o solo possui uma capacidade menor de infiltração e maior de retenção, saturando com uma maior facilidade quando comparado com a faixa lateral. Esse fato provoca o escoamento superficial que, além de retirar as camadas superficiais e férteis do solo, pode potencializar o processo erosivo.

Com base nos resultados obtidos e nas correlações descritas anteriormente, evidencia-se que a faixa territorial utilizada como trilha está iniciando um processo de compactação, afirmação baseada no conceito de vários autores, dentre os quais Becker apud Kertzman (1996). Este cita a compactação como sendo o processo que resulta num aumento de densidade do solo pela diminuição do espaço poroso, fato observado na área de estudo. Assim, verifica-se que a alteração dessas propriedades do solo (indicadores) denunciam a compactação.

Uma forma de minimizar a compactação é promover a incorporação de matéria orgânica no solo. De forma natural, a serrapilheira realiza esta função. Assim, a adição de restos vegetais ao longo do traçado da trilha pode minimizar os impactos gerados pelo pisoteio, seja pelo próprio amortecimento da pressão exercida na superfície, seja pela incorporação da matéria orgânica no solo, melhorando assim seus parâmetros quanto a densidade e porosidade.

Assim, o entendimento do processo de alteração das propriedades físicas do solo diante do deslocamento de pessoas, pode auxiliar no processo de planejamento, implantação e manutenção de trilhas.

\section{REFERÊNCIAS}

BOÇON, R. Caracterização de solos, vegetação e público alvo como indicadores no planejamento de trilhas interpretativas. Dissertação apresentada ao Curso de Pós Graduação em Agronomia da Universidade Federal do Paraná, como requisito parcial a obtenção do grau e título de mestre em Agronomia. Curitiba, 2002.

EMBRAPA. Empresa Brasileira de Pesquisa Agropecuária Serviço Nacional de Levantamento e Conservação de Solos. (EMBRAPA/SNLCS). Levantamento e 
Reconhecimento dos Solos do Estado do Paraná. EMBRAPA/SNLCS/SUDESUL/IAPAR. 1984.

EMBRAPA - CNPS. Sistema Brasileiro de Classificação de Solos. Brasilia: EmbrapaSPI; Rio de Janeiro: Embrapa-Solos, 2006.

JORGE, José Antônio. Física e Manejo dos Solos Tropicais - Campinas: Instituto Campineiro de Ensino Agrícola, 1985.

KERTZMAN, Fernando, Faciolla. Modificações na Estrutura e no Comportamento de um Latossolo Roxo Provocadas Pela Compactação. Tese apresenta à Faculdade de Filosofia, Letras e Ciências Humanas, do Departamento de Geografiada Universidade de São Paulo, para obtenção do título de Doutor em Geografia Física. São Paulo,1996.

LEPSCH, IGO, F; Formação e Conservação dos Solos. São Paulo, SP: Oficina de Texto, 2002.

MAGRO, T. C. Impactos do uso público em uma trilha no planalto do Parque Nacional de Itatiaia. São Carlos, 1999. Tese (Doutorado), Escola de Engenharia de São Carlos - universidade de São Paulo.

OLIVEIRA, José Flávio de; SERRANO, Célia M. T. Diretrizes para uma Política Estadual De Ecoturismo: proposta. São Paulo : SMA, 1997.

PAGANI, M. I.- As trilhas interpretativas da natureza e o ecoturismo. In: LEMOS, A. I. G. (org). Turismo impactos sócio ambientais. São Paulo: ed. Hucitec,1998.

PREVEDELLHO, C.L. Física do Solo com Problemas Resolvidos. Curitiba, 1996. Pg. 8-16.

RUSHIMANN, D.V.M. Turismo e Planejamento Sustentável: A proteção do meio ambiente. Campinas, SP: Papirus, 1997.

STRUMINSKI, EDSON. Parque Estadual Pico do Marumbi. Curitiba, PR: UFPR, 2001.

TAKAHASHI, L. Y. Caracterização dos Visitantes, Suas Preferências e Percepções e Avaliação dos Impactos da Visitação Pública em Duas Unidades de Conservação do Estado do Paraná. Curitiba, 1998. Tese (Doutorado em Ciências Florestais) Universidade Federal do Paraná.

TORMENA, Cassio Antonio. Resistência a Penetração e Porosidade em Plantio Direto Influênciados Por Preparos Pré-Implantação, Calagem e Tráfego. Dissertação apresentada ao curso de pós-graduação em Agronomia, como requisito parcial a obtenção do grau de mestre UFPR, 1991. 